\title{
THE PAST, PRESENT AND FUTURE OF THE GEO-ENVIRONMENT IN JAPAN
}

\author{
Hideo Komine ${ }^{\mathrm{i})}$ and Yasutaka Watanabe ${ }^{\mathrm{ii}}$
}

\begin{abstract}
This paper is an overview of the status in geo-environment research in the past, the present and the future in Japan as witnessed by the publications in "Soils and Foundations" over the years. The authors have paid special attention to the geotechnical researches concerning technologies of waste disposal, including radioactive waste disposal, the reuse and recycle of by-product and waste, the evaluation of the environmental impact of waste and by-product, and countermeasures and adaptations to the contamination of ground/groundwater. Some representative papers on the geo-environment published in "Soils and Foundations" have been drawn on heavily in this paper. The commentary provided by the authors is largely from a geo-environmental perspective. In addition, the authors have also paid attention to geotechnical issues in the research.
\end{abstract}

Key words: environmental geotechnics, ground/groundwater contamination, recycle of by-product, waste disposal technology, radioactive waste disposal

\section{INTRODUCTION}

The authors have been invited to write an overview of the research situation of the geo-environment in the past, the present and the future through an analysis of what has been published over the years in "Soils and Foundations". The authors have broken up the bigger concept of geo-environment into the following four research themes; the technologies of waste disposal including radioactive waste disposal, the reuse and recycling of by-product and waste, the evaluation of the environmental impact of waste and by-product, and countermeasures and adaptations to contaminations of ground/groundwater.

Over the course of the 20th century geotechnical engineering made huge contributions to society. As the 21 st century unfolds, it is clear that the future contribution of geotechnical engineering will not be limited to the construction of infrastructure, but will also be to the sustainability of our society. The authors themselves have published in the field of geo-environment research only over the last 10 to 20 years, but have attempted to cover research trends over a much larger time frame and also give a future perspective of the geo-environment in this article. It is our hope that persons much older and more experienced will be satisfied with the content of this paper. We are, however, relatively young and inexperienced, and as such would like to beg forgiveness if the content of this paper falls short of our goals. Our biggest challenge in writing this was to write a future perspective and explain the "dream" of the geo-environment for the benefit of young students who will make their mark in this research area.

\section{THE RELATIONSHIP BETWEEN SUSTAINABLE DEVELOPMENT AND GEOTECHNICAL ENGINEERING}

Over the last ten years, geotechnical engineering has contributed to solving some major social problems, including the recycling of by-product and the development of new technologies for disposing of waste from the viewpoint of sustainable development of society. The results of the many research endeavours have been published in "Soils and Foundations" and the proceedings of annual conferences and symposiums of the Japan Geotechnical Society. Table 1 shows the number of articles in the past Environmental Geotechnics Symposium in Japan. Clearly, the number of articles being published in the area of geo-environment research is increasing incrementally. Almost all of the technical articles which have been published in "Soils and Foundations" are related to the recycling of by-products and the technologies of waste disposal.

An important question for us to address as we approached the task of writing an overview in our field was when geotechnical research did begin to make a contribution to the environment and/or the sustainable development of society?

From the perspective of the first author, the term of "pollution" was often heard when he was a small child at

i) Doctor of Engineering Professor, Ibaraki University, Department of Urban and Civil Engineering, Ibaraki, Japan (hkomine@ mx.ibaraki.ac.jp).

ii) Master of Engineering JSPS Research Fellow, Ibaraki University, Department of Urban and Civil Engineering, Ibaraki, Japan. The manuscript for this paper was received for review on June 3, 2010; approved on September $29,2010$. 
Table 1. Number of articles in the past Environmental Geotechnics Symposium

\begin{tabular}{c|c|c|c}
\hline Number & Month, Year & Place & Number of articles \\
\hline 1 & May, 1994. & Tokyo & 40 \\
\hline 2 & November, 1997. & Kyoto & 44 \\
\hline 3 & November, 1999. & Tokyo & 58 \\
\hline 4 & May, 2001. & Tokyo & 56 \\
\hline 5 & July, 2003. & Tokyo & 52 \\
\hline 6 & May, 2005. & Sapporo & 68 \\
\hline 7 & August, 2007. & Fukuoka & 63 \\
\hline 8 & July, 2009. & Akita & 87 \\
\hline
\end{tabular}

school i.e., about 35 years ago. However, terms like “environmental problem" and "sustainable development" were not part of the vernacular back then. Indeed, it almost seems that when we hear the word "pollution", we think someone is talking about air pollution. Indeed the generation of oxidant smog was such a big problem that even school children were frequently sent back indoors rather than being allowed to continue with physical education classes outdoors. Almost all the school children of the day hoped that this "pollution" problem would go away as soon as possible simply because they preferred PE classes to book learning. Thanks to the efforts made by researchers and engineers at that time to solve air pollution, the air conditions today are very comfortable.

Despite the lack of social discussion, and therefore the lack of awareness among the general public, we were sure that ground settlement was also a pollution problem at that time. Since geotechnical engineers were good at researching from the viewpoint of mechanics, they were able to find and solve research problems concerning ground settlement using the many consolidation theories that geotechnical community had developed over time.

These days, as in the past, public awareness tends to be high when there is an attractive issue at hand. Ordinary people had little interest in the ground or in groundwater, or in a matter related to the ground. We are sure that the 1978 ground contamination at Love Canal in the United States of America was the first affair to get the public's attention. When the toxic waste buried under a neighborhood was found to have such a profound effect on the health and well-being of the residents, everyone started to take notice. Since 1978, the ground environment has been a focus of attention for geotechnical. Indeed, there have been many cases of ground/groundwater contamination that have come to light since 1978 along with the redevelopment of industrial factory sites in Japan. Accordinglly, statutes concerning the geo-environment were revised in the $1980 \mathrm{~s}$. Interest in geo-environment at that time led to some publications of relevant research "Soils and Foundations'.

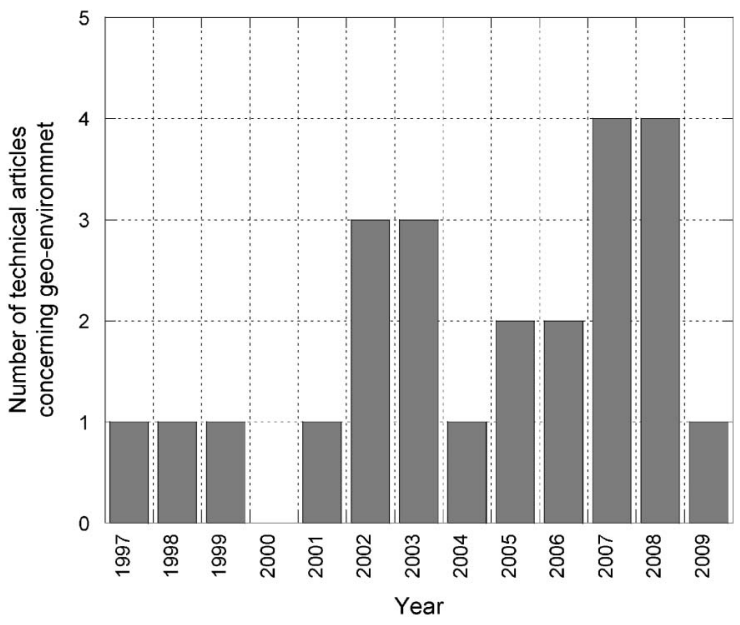

Fig. 1. Number of technical articles concerning geo-environment in the past Soils and Foundations

\section{ARTICLES RELATED TO GEO-ENVIRONMENT IN THE PAST "SOILS AND FOUNDATIONS"}

The authors have selected the articles related to geo-environment in the past "Soils and Foundations" according to the key technical terms, such as technologies for waste disposal, evaluation and remediation of contaminated ground and groundwater, techniques of reuse/recycle of by-product and waste. Figure 1 shows the number of technical articles concerning the geo-environment in past issues of "Soils and Foundations". As shown in Fig. 1, there were very few articles in the 1990s, however, the number of articles began increasing in the 2000s. Table 2 shows the titles and authors of the technical articles concerning geo-environmental issues in past issues of "Soils and Foundations". Table 2 shows that there have been many studies about the recycling engineering of by-product and/or waste, the technology for disposing of waste, including radioactive waste, and the environmental impact on soil/waste/groundwater. In the next section, we review a few selected articles from all those listed in Table 2 .

\section{REVIEW OF THE REPRESENTATIVE ARTICLES RELATED TO GEO-ENVIRONMENT IN THE "SOILS AND FOUNDATIONS",}

Having reviewed the technical articles related to geoenvironment in past issues of "Soils and Foundations", we would like to introduce some representative articles from the following three categories: 1) technologies for waste disposal (water proof), 2) evaluation and remediation of contaminated ground and groundwater, and 3) techniques of reusing/recycling of by-product and waste and the environmental impact assessment.

Firstly, the following articles related to technologies for waste disposal have been especially worthy of note. Komine and Ogata (1999) presented the swelling characteristics of sand-bentonite mixture for radioactive waste disposal (see Fig. 2). The dependence of the swelling 
Table 2. Titles and authors of the technical articles concerning geo-environment appeared in the past "Soils and Foundations"

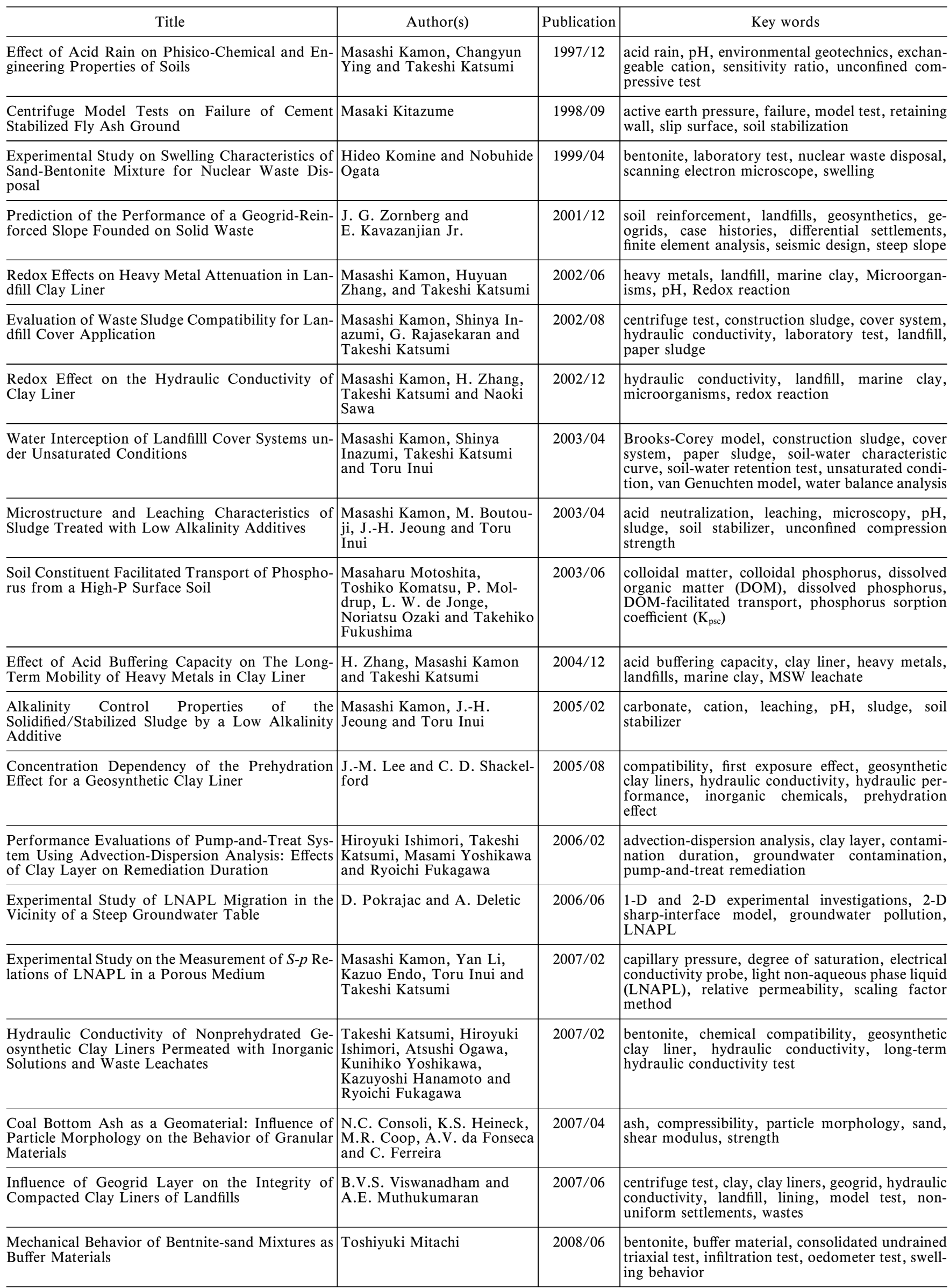


Table 2. (continue)

\begin{tabular}{|c|c|c|c|}
\hline Title & Author(s) & Publication & Key words \\
\hline $\begin{array}{l}\text { Effects of Water Content Distribution on Hydraul- } \\
\text { ic Conductivity of Prehydrated GCLs against Cal- } \\
\text { cium Chloride Solutions }\end{array}$ & $\begin{array}{l}\text { Takeshi Katsumi, Hiroyuki } \\
\text { Ishimori, Atsushi Ogawa, } \\
\text { Satoshi Maruyama and } \\
\text { Ryoichi Fukagawa }\end{array}$ & $2008 / 06$ & $\begin{array}{l}\text { chemical resistance, geosynthetic clay liner, } \\
\text { hydraulic conductivity, prehydration }\end{array}$ \\
\hline $\begin{array}{l}\text { Formulation of a Dusty Gas Model for Multi-com- } \\
\text { ponent Diffusion in the Gas Phase of Soil }\end{array}$ & Yoshihiko Hibi & $2008 / 06$ & $\begin{array}{l}\text { dusty gas model, finite element method, multi- } \\
\text { component diffusion, numerical analysis, unsatu- } \\
\text { rated soil }\end{array}$ \\
\hline $\begin{array}{l}\text { Characteristics of Strength for Hydraulic Fractur- } \\
\text { ing of Buffer Material }\end{array}$ & $\begin{array}{l}\text { Akira Kobayashi, Kiyohito } \\
\text { Yamamoto and Shohei } \\
\text { Momoki }\end{array}$ & $2008 / 08$ & $\begin{array}{l}\text { bentonite, dry density, hydraulic fracturing, } \\
\text { laboratory test, nuclear waste disposal, swelling, } \\
\text { water content }\end{array}$ \\
\hline $\begin{array}{l}\text { Role of Fly Ash on Strength and Microstructure } \\
\text { Development in Blended Cement Stabilized Silty } \\
\text { Clay }\end{array}$ & $\begin{array}{l}\text { S. Horpibulsuk, R. Rachan } \\
\text { and Y. Raksachon }\end{array}$ & $2009 / 02$ & $\begin{array}{l}\text { blended cement, cementation, dispersion, fabric, } \\
\text { fly ash, hydration, microstructure, pore size distri- } \\
\text { bution, scanning electron microscope, strength, } \\
\text { thermal gravity analysis }\end{array}$ \\
\hline
\end{tabular}

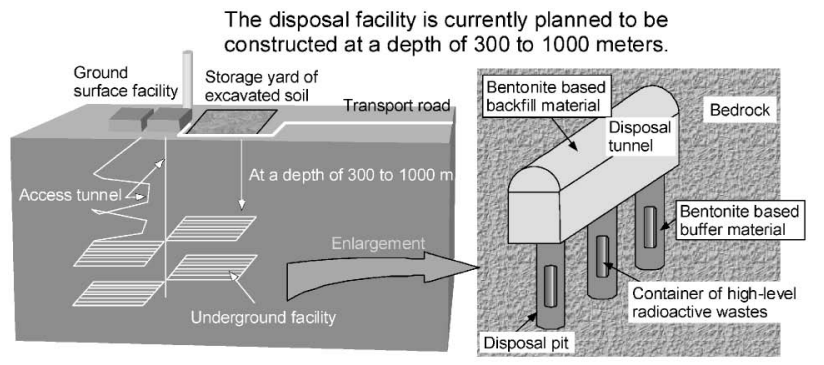

(a) High-level radioactive waste disposal facility

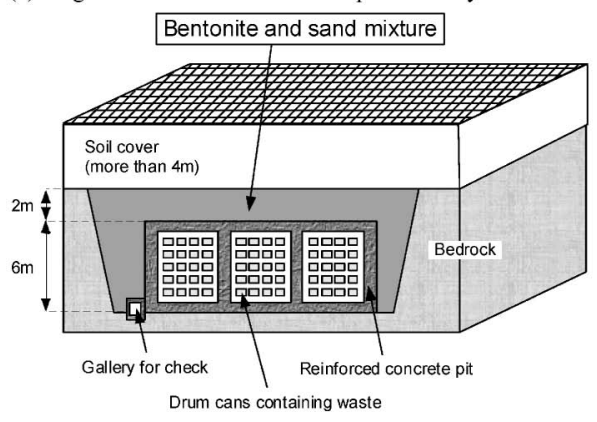

(b) Low-level radioactive waste disposal facility

Fig. 2. Utilization of bentonite-based material in underground radioactive waste disposal facilities

characteristics of sand-bentonite on the dry density and bentonite content of mixtures was clarified. In their investigation, their scanning electron microscope observations under a controlled temperature and vapor pressure supported the swelling mechanism from the viewpoint of clay mineralogy, as shown in Fig. 3. Kamon et al. (2002) investigated the effects of reduction-oxidation (redox) reactions on heavy metal attenuation in the landfill clay liner of various solid waste landfill sites located in coastal areas. Bacterial culture batch tests were performed, and the effect of both redox potential and $\mathrm{pH}$ on the solubility of zinc and iron was clarified. Kamon et al. (2003a) investigated the soil-water characteristic curve of paper sludge and construction sludge for application as landfill barrier materials, which is the final disposal technique included in the "reuse of by-product" concept. Katsumi et al. (2008) focused on the use of geosynthetic clay liners
(GCLs) in waste containment facilities, and investigated the effects of water content distribution on the hydraulic conductivity of the prehydrated GCLs due to the calcium chloride solution. The chemical resistance of soils to various concentrations of inorganic solution was discussed.

With regard to the evaluation and remediation of contaminated ground and groundwater, Ishimori et al. (2006) numerically simulated the pump-and-treat remediation system at contamination sites using an advectiondispersion analysis. The assumed contamination was trichloroethylene, a dense non-aqueous phase liquids (DNAPLs). For the analysis, several parameters, for example, the hydraulic conductivity and the thickness of the clay layer were considered. The effect of the duration of contamination on the remediation duration was discussed. Kamon et al. (2007) targeted light non-aqueous phase liquids (LNAPLs). In order to measure the saturation-capillary pressure relationship in the LNAPLwater system, electrical conductivity probes and tensiometers were used.

On the subject of reusing by-product materials or waste and environmental impact assessments, Kamon et al. (2003b) evaluated the potential use of low alkalinity additives in order to minimize the environmental impact in the treatment of dredged sludge. Stabilized samples were produced using a low alkalinity additive (mainly gypsum and a polymer), and the unconfined compression strength, microstructure, $\mathrm{pH}$, acid neutralization capacity and leachate were investigated. Consoli et al. (2007) presented the mechanical properties of coal bottom ash as a geomaterial. The high-pressure isotropic compression, ring shear and bender elements were tested using coal bottom ash.

In the research introduced above, batch leaching and column leaching test apparatuses were frequently used. Figures 4 and 5 show the batch leaching and column leaching test apparatuses used by the authors' research groups. These test apparatuses are effective in carrying out an environmental impact assessment of by-product and wastes utilization. The batch leaching test is the test specified in the Public Notice No. 46 of the Ministry of Environment (JLT-46), which is based on the Environ- 


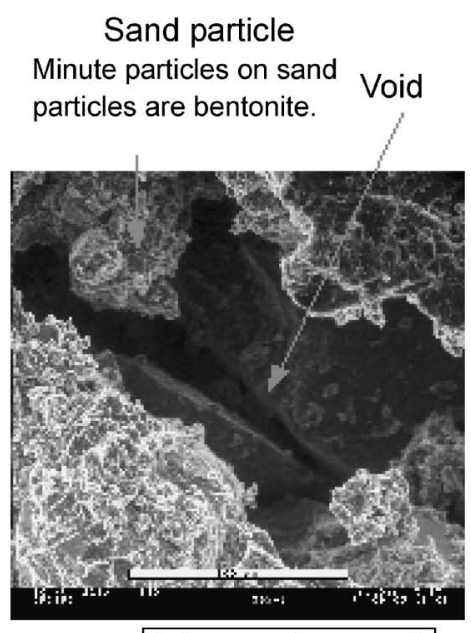

Before water supply
Process of filling the voids by the volume increase of bentonite can be observed.

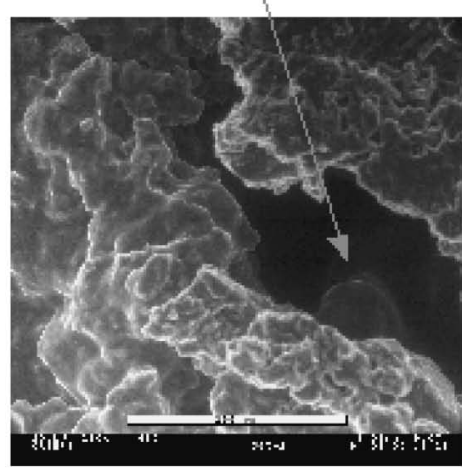

During water supply
The voids are filled completely by the volume increase of bentonite absorbing water.

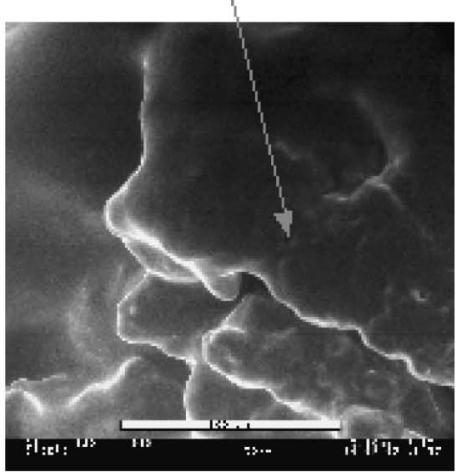

After water supply

Fig. 3. Observation of swelling behavior of bentonite in the sand-bentonite mixture at bentonite content 50\% (After Komine and Ogata, 1999)

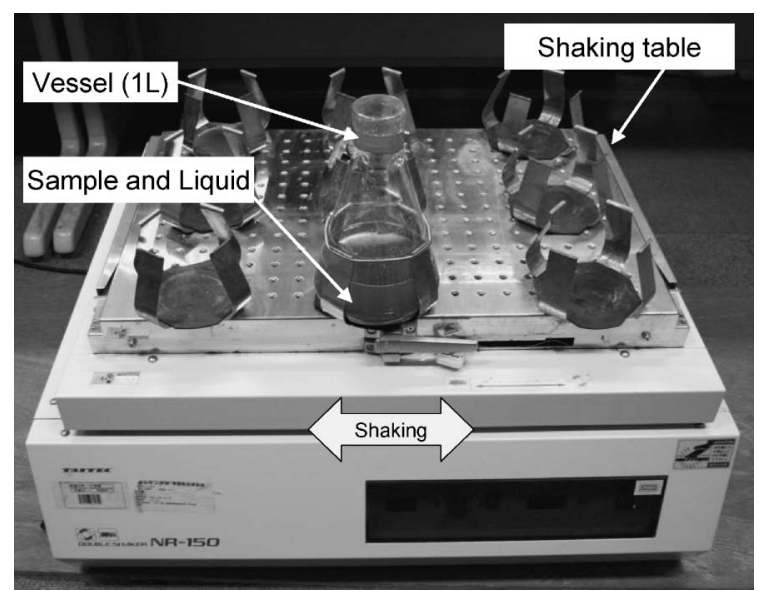

Fig. 4. Shaking machine for batch leaching test in Ibaraki University

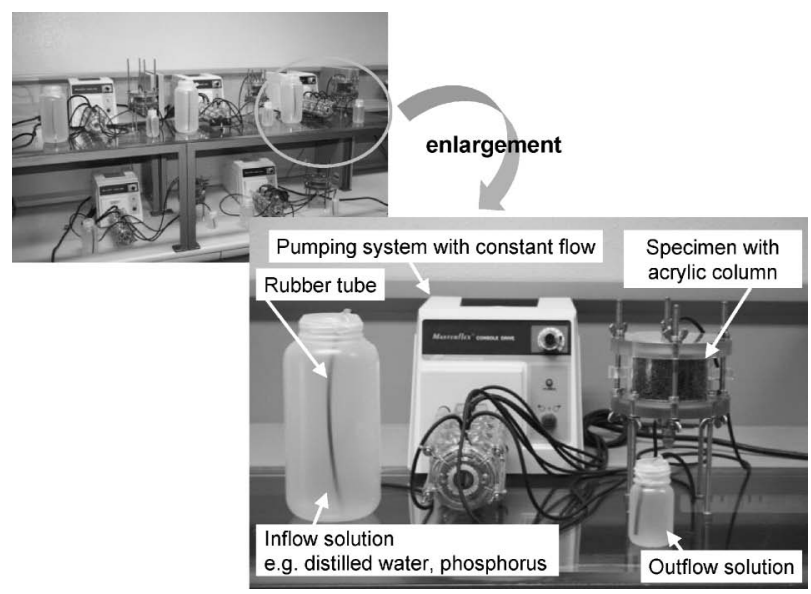

Fig. 5. Column leaching test apparatus in Ibaraki University

mental Standard Index for Soil Pollution. The column leaching test can simulate actual site conditions, such as dry density, thickness of the material and flow velocity.
The earliest article to including a geo-environmental perspective was presumably a study of the effect of acid rain on physic-chemical and engineering properties of soils (Kamon et al., 1997). The key words of the article included "environmental geotechnics" and "exchangeable cation". Infiltration and soak tests which correspond to column leaching and tank leaching tests were performed to simulate the erosion process of soils caused by acid rain.

While the selection of articles above of course is biased, it provides an understanding of how research perspective has progressed and also highlights the more remarkable work in geo-environmental engineering. As mentioned previously, the increase in the number of articles related to geo-environment indicates that the field of geo-environmental engineering is expanding and diversifying.

\section{FUTURE PERSPECTIVE OF GEO-ENVIRONMENT}

In "Soils and Foundations", the focus of the published geotechnical articles has been on the following: 1) technologies for waste disposal (water proof), 2) the evaluation and remediation of contaminated ground and groundwater, and 3) techniques for the reuse/recycling of by-product and waste and environmental impact assessments. Recently, there have been new research fields which have been given attention in various countries around the world. The Canadian Geotechnical Journal and the Journal of Geotechnical and Geoenvironmental Engineering of the American Society of Civil Engineers have published a wide array of articles concerning geo-environment. After considering these articles and the recent demands from society, we believe the future of geo technical engineering will be on developing the following technologies in order to solve the problems concerning geo-environment.

a) Technology for solving problems of environmental impact of soils and rocks which naturally contain arsenic and lead, fluorine and boron, etc. 
b) Technology for managing the huge amount of waste inevitably created after huge natural disasters such as great earthquakes and/or large floods.

c) Technology for communicating and explaining the importance of the construction of waste disposal facilities to residents living in the area of the proposed sites and the general public at large.

d) New technology for evaluating the environmental impact of wastes and by-products which can simulate the circumstances of reusing and recycling

The above technologies are immediately required to develop solutions to each of the problems listed. These perspectives may well all stem from one aspect of creating a sound material-cycle society, namely, the balance between social demands and the shortage of natural resources. Geo-environmental researchers and engineers should also be developing technologies for addressing the various problems resulting from the various global environmental issues. Indeed, in the Fourth Assessment Report of Intergovernmental Panel on Climate Change (IPCC, 2007), such a suggestion was made. Yasuhara et al. (2010) suggested that climate change tends to exacerbate geo-disasters, e.g., the compound disaster between rainfall severity and great earthquakes. To mitigate the effects of climate change on geo-disasters, it is important to reduce greenhouse gases (GHGs): $\mathrm{CO}_{2}, \mathrm{CH}_{4}$ and $\mathrm{N}_{2} \mathrm{O}$. Therefore, besides the conventional technologies of geoenvironmental engineering, GHG reduction technologies will need to be employed in the future. In fact, Komine et al. (2009) pointed out the vulnerability of river-levee and bank infrastructures made of soil material due to the rise in the sea-water level as a result of global warming. It is reasonable to assume that the number of technical articles concerning global warming and GHG reduction will increase. Also Simpson and Tatsuoka (2008) indicated the importance of the mitigation of climate change from the following perspectives: unsaturated soils, shrinkable clays, slope stability caused by drying and wetting, as well as the reduction of the total construction energy used and $\mathrm{CO}_{2}$ emissions.

Finally, we would like to express our view that "Soils and Foundations"' will play a very important role in making it possible for geotechnical engineers to meet various social demands, including finding the best ways to address the many global environmental issues we are facing. It is our hope that the geo-environmental engineering community is successful in dealing with the many issues we work with as geotechnical engineers.

\section{REFERENCES}

1) Consoli, N. C., Heineck, K. S., Coop, M. R., Fonseca, A. V. and Ferreira, C. (2007): Coal bottom ash as a geomaterial: Influence of particle morphology on the behavior of granular materials, Soils and Foundations, 47(2), 361-373.

2) IPCC (2007): IPCC Fourth Assessment Report: Climate Change 2007, Synthesis Report Summary of Policymakers.

3) Ishimori, H., Katsumi, T., Yoshikawa, M. and Fukagawa, R. (2006): Performance evaluations of pump-and-treat system using advection-dispersion analysis: Effects of clay layer on remediation duration, Soils and Foundations, 46(1), 45-59.

4) Kamon, M., Ying, C. and Katsumi, T. (1997): Effect of acid rain on physico-chemical and engineering properties of soils, Soils and Foundations, 37(4), 23-32.

5) Kamon, M., Zhang, H. and Katsumi, T. (2002): Redox effects on heavy metal attenuation in landfill clay liner, Soils and Foundations, 42(3), 115-126.

6) Kamon, M., Inazumi, S., Katsumi, T. and Inui, T. (2003a): Water interception of landfill cover systems under unsaturated conditions, Soils and Foundations, 43(2), 1-16.

7) Kamon, M., Boutouji, M., Jeoung, J. and Inui, T. (2003b): Microstructure and leaching characteristics of sludge treated with low alkalinity additives, Soils and Foundations, 43(2), 105-114.

8) Kamon, M., Li, Y., Endo, K., Inui, T. and Katsumi, T. (2007): Experimental study on the measurement of $S$ - $p$ relations of LNAPL in a porous medium, Soils and Foundations, 47(1), 33-45.

9) Katsumi, T., Ishimori, H., Ogawa, A., Maruyama, S. and Fukagawa, R. (2008): Effects of water content distribution on hydraulic conductivity of prehydrated GCLs against calcium chloride solutions, Soils and Foundations, 48(3), 407-417.

10) Komine, H. and Ogata, N. (1999): Experimental study on swelling characteristics of sand-bentonite mixture for nuclear waste disposal, Soils and Foundations, 39(2), 83-97.

11) Komine, H., Yasuhara, K. and Murakami, S. (2009): Simplified evaluation on impact of soil materials for levee and river-bank by sea-water level raising due to global warming, Japanese Geotechnical Journal, 4(2), 185-195 (in Japanese with English abstract).

12) Simpson, B. and Tatsuoka, F. (2008): Geotechnics: the next 60 years, Geotechnique, 58(5), 357-368.

13) Yasuhara, K., Komine, H., Murakami, S., Chen, G. and Mitani, Y. (2010): Effects of climate change on geo-disasters in coastal zones, Journal of Global Environmental Engineering, 15, 15-23. 